\title{
ANALISIS ELEMEN VISUAL GAME "PAMALI" DENGAN MENGGUNAKAN PENDEKATAN TEORI MIMESIS PLATO
}

\author{
Fachry Fauzhan ${ }^{1}$, Eric Alvian², Septian Andreanto ${ }^{3}$, Nurulfatmi Amzy ${ }^{4}$ \\ Program Studi Desain Komunikasi Visual, \\ Fakultas Bahasa dan Seni, Universitas Indraprasta PGRI \\ Jl. Nangka No. 58 C, Tanjung Barat, Jakarta Selatan, 12530, Indonesia
}

okrkic@gmail.com

\begin{abstract}
Abstrak
Game merupakan sebuah jenis media hiburan yang diminati berbagai kalangan masyarakat pada saat ini. Di balik perannya yang semakin diminati, game memiliki elemen-elemen pendukung yang membantu perannya sebagai media hiburan yang paling diminati. Salah satu elemen penting dalam sebuah game adalah elemen visualnya. Hal ini disebabkan elemen visual memiliki daya untuk bisa memberikan koneksi antara pesan atau cerita yang ingin disampaikan oleh pembuat game kepada para pemain game tersebut. Yang akan dibahas dalam artikel ini adalah Game "Pamali", salah satu game yang memiliki elemen visual menarik untuk di bahas. Metode yang digunakan dalam penelitian ini adalah metode deskriptif dengan pendekatan teori filsafat seni, yaitu seni sebagai mimesis (imitasi) yang diusung oleh Plato. Penelitian ini akan menunjukkan bahwa visual game "Pamali" adalah sebuah imitasi (tiruan) dari konsep ideal yang ada di kepala desainer game tersebut.
\end{abstract}

Kata kunci: Game, Elemen,Visual, Realitas, Mimesis

\begin{abstract}
Game is a kind of entertainment media that is gaining so much interest among people nowadays. That is supported by elements applied in it. One of the important things in a game is the visual element. It has the potency to give a connection between the game's storyline made by its designer and the player. This paper focuses on a game called Pamali. It is an example of a game that has strong visual elements in it. By using the descriptive method with Plato's mimesis (imitation) theory as an approach, this study will analyze the visual elements used in the game. The result shows that visual elements in the game are imitations of the ideal concept from the game's designer.
\end{abstract}

Keywords: Game, visual elements, mimesis

Correspondence author: Fachry Fauzhan,okrkic@gmail.com, Jakarta, and Indonesia (1) (1)

This work is licensed under a CC-BY-NC 


\section{PENDAHULUAN}

Game merupakan jenis hiburan yang disukai oleh semua orang dari usia anak-anak, dewasa maupun tua. Selain digunakan untuk menghilangkan kepenatan dalam beraktivitas, sebuah game juga dapat berfungsi untuk melatih pola pikir seseorang untuk mencari solusi memecahkan suatu permasalahan yang ada di sebuah game.

Dalam perkembangannya sejak game generasi pertama di tahun 1972, game terus mengalami peningkatan seiring dengan arus kemajuan teknologi. Saat ini game sudah dapat dinikmati berbagai kalangan dengan beragam genre dengan konsep dan tema yang berbeda-beda sesuai dengan target yang di tuju oleh produsen game (game developer).

Terkait dalam fungsinya sebagai jenis media hiburan bagi berbagai kalangan, konsep game saat ini telah berevolusi menjadi sebuah game yang bersifat interaktif. Warsita (2008) menjelaskan bahwa pengertian interaktif adalah suatu hal yang terkait dengan komunikasi dua arah ataupun suatu hal yang bersifat saling melakukan aksi, saling aktif dan saling memberikan hubungan satu sama lain yang memberikan timbal balik satu sama lainnya. Dalam konsep keterkaitan komunikasi 2 arah, game membangun koneksi kepada pemain melalui program dan elemen-elemen pendukung yang dipadukan agar pemain dapat terikat terhadap alur cerita atau konsep di dalam permainan. Di antara elemen-elemen pendukung di dalam game, hal yang paling berpengaruh dalam pembangunan koneksi antara pemain dengan ide utama yang di berikan oleh pembuat game (game developer) adalah elemen visual. Elemen visual dalam game berfungsi sebagai sebuah unsur yang mewujudkan tiap-tiap konsep ide utama dalam bentuk aset yang telah dirancang oleh game developer.

Sebagai contoh dalam penjelasan-penjelasan tersebut, peneliti mengambil objek untuk dijadikan sumber penelitian, yaitu sebuah game yang dikembangkan oleh salah satu game developer asal bandung, Story Tale Studios.

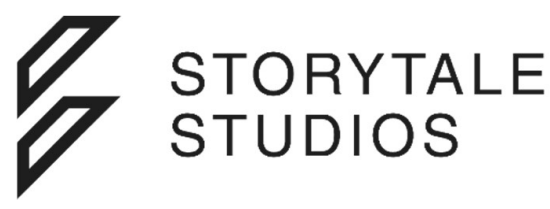

Gambar 1. Logo Storytal Studios

Storytale Studios merupakan developer game asal kota Bandung yang membuat dan mengembangkan sebuah game folklore (cerita rakyat) horror bernama "PAMALI"." "PAMALI" adalah sebuah game yang di buat untuk dapat memberikan sebuah sensasi mengenai pengalaman terhadap sebuah budaya supranatural (mistis) yang biasa dipercayai dan diminati oleh masyarakat Indonesia. Terutama mengenai latar belakang kepercayaan masyarakat terhadap keberadaan entitas-entitas supranatural, seperti cerita-cerita rakyat yang berkaitan dengan pengalaman supranatural. Contohnya, kisah mistis masyarakat tentang rumah kosong yang dihuni hantu, kuntilanak, pocong, tuyul, jenglot dan lain-lain.

Storytale Studios memiliki ide utama untuk memasukan unsur-unsur supranatural yang secara umum dapat memikat rasa penasaran dan ketakutan bagi berbagai kalangan di Indonesia. Mereka membangun sebuah ide yang memiliki patokan berupa sebuah realitas yang dekat bagi calon pemain dalam berbagai kalangan, dengan membangun elemen-elemen pendukung yang dipadukan oleh alur cerita dengan konsep simulasi dimana pemain ditemukan pada sebuah dunia tiruan dari apa yang ada di dunia nyata baik yang di wujudkan dalam bentuk elemen-elemen visual berupa aset benda, latar tempat, karakter yang saling berhubungan menjadi sebuah konsep visual pada game yang menarik untuk diulas dalam pembahasan artikel ini.

\section{METODE PENELITIAN}

Dalam membedah game ini, peneliti menggunakan metode penelitian deskriptif. Metode penelitian deskriptif merupakan usaha dalam mengeksplorasi dam mengklarifikasi suatu objek 
dengan cara mendeskripsikan sejumlah variabel yang berkenaan dengan objek yang diteliti (Mulyadi, 2011: 123). Penelitian ini diikuti dengan pendekatan teori Filsafat Seni tentang Seni sebagai mimesis (imitasi) yang diusung oleh Plato. Konsep plato tentang seni sebagai mimesis berdasar pada prinsip dualismemya, yaitu paham terhadap dua dunia. 1) Dunia ide, yang merupakan sebuah bentuk konsep tentang sesuatu yang bersumber dalam pikiran manusia sendiri dan tidak dapat tersentuh oleh alat indrawi manusia, dan 2) dunia indrawi, tempat segala hal yang dapat ditangkap oleh indrawi manusia. Di antara keduanya, yang dianggap realita adalah dunia ide, karena di sana letaknya konsep kesempurnaan, sebuah kebenaran. Danyati (2018: 2-3) mengatakan bahwa seni adalah tiruan dari konsep ide seniman. Karya seninya tidak akan pernah menyamai ide yang ada pada konsepsi seniman terkait objek tersebut. Kekokohan/kesempurnaan konsep dalam dunia ide adalah yang dianggap benar. Menurut Plato, Kebenaran adalah tolak ukur keindahan. Maka, yang indah adalah yang benar.

Dalam pengumpulan data peneliti menerapkan metode kualitatif, di mana peneliti menggunakan teori-teori atau data yang telah dibuat melalui buku, jurnal, ataupun artikel dari dalam web, untuk dijadikan sebagai sumber acuan pembahasan penelitian, agar pembahasannya dapat memiliki dasar yang kuat sebagai sebuah artikel ilmiah.

\section{HASIL DAN PEMBAHASAN}

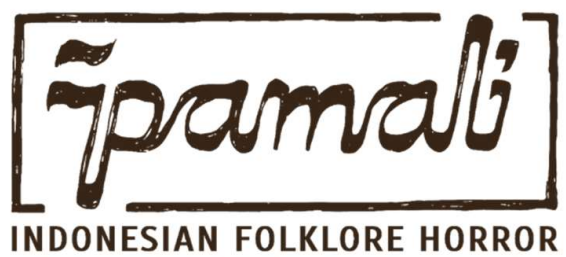

Gambar 2. Logo game

Objek pembahasan dalam artikel ini akan berfokus pada salah satu game besutan Storytale Studio, yang sebelumnya telah dijelaskan. Storytale Studio sebagai deveploper merancang sebuah game bernama "Pamali", "Pamali" adalah game bergenre simulation dengan tema Folklore horor yang dibuat dengan konsep pengaplikasian cerita-cerita horor lokal indonesia. Cerita horor yang dipilih merupakan cerita yang umum nya diketahui oleh hampir seluruh kalangan masyarakat, konsep ini dipilih dikarenakan hal-hal seputar supranatural masih mendapatkan perhatian lebih berbagai kalangan masyarakat di indonesai sehingga tema ini cukup menjanjikan apabila diaplikasikan ke dalam sebuah game yang akan diproduksi di masyarakat luas.

"Pamali" membawa kita ke sebuah aspek simulasi yang dikemas ke dalam beberapa macam skenario budaya astral nan tabu. Contohnya, pemain yang ditugaskan untuk membersihkan sebuah rumah kosong tanpa harus menganggu ketenangan para mahluk-mahluk astral yang mendiami rumah tersebut. Atau tantangan yang berkaitan tentang sebuah pantangan tabu (Pamali).

Dalam perancangannya game "Pamali" dibuat dengan menerapkan aspek kearifan lokal pada unsur cerita, elemen visual, dan berbagai hal mendetail lainnya yang sesuai dengan realitas atau secara umum diketahui dan dimiliki oleh masyarakat. Perancangan tersebut dibuat agar pemain dapat merasakan wujud dari pengalaman mistis yang divisualisasikan kedalam sebuah game horor yang dapat memberikan kesan yang menggugah bagi para pemain.

Elemen visual menjadi sebuah unsur terpenting dalam tercapainya ide utama, konsep yang membentuk elemen visual pada game ini dibuat menyesuaikan realitas agar koneksi (pesan) persuasif tentang kengerian dapat tersampaikan dengan baik kepada seluruh pemain.

Sebagai sebuah unsur terpenting dalam tercapainya tujuan utama bagi game developer di pasaran elemen visual dalam game "Pamali" merupakan unsur yang layak untuk di analisa konsep 
dan tujuannya sesuai dengan metode penelitian yang telah dosesuaikan, yaitu penganalisaan elemen visual melalui kacamata seni sebagai mimesis (imitasi). Dalam pembahasaan ini peneliti akan menyandingkan elemen visual di dalam game yang merupakan sebuah konsep yang lahir dari dunia ide manusia dengan benda yang dijadikan pakem imitasi dari dunia indrawi yang berasal dari sebuah realitas yang telah diketahui dan dapat dirasakan oleh manusia.

Dari serangkaian konsep elemen visual yang terdapat dalam game "Pamali", peneliti telah memilih sebagian bentuk visual dari potongan tiap scene pada game yang paling sesuai dengan metode penelitian yang telah peneliti tentukan, antara lain konsep visual tersebut berupa sebuah bentuk ilustrasi dari beragam realita alam indrawi yang mencakup latar tempat, latar suasana, aset, dan karakter bernuansa folklore, Konsep ini berperan penting dalam keberhasilan sebuah cerita yang membangun sebuah koneksi dan daya tarik para pemain . seperti yang direncanakan oleh pembuat game. Berikut adalah elemen visual dari game "Pamali" yang telah peneliti analisa.

\section{Analisis Elemen Visual}

Dalam penilaian seni sebagai mimesis, Plato menjelaskan bahwa metode ini berdasar pada konsep dua dunia, diantaranya dunia ide dan dunia indrawi. Dalam proses menganalisa, peneliti mengambil contoh pertama dari potongan scene dari game "Pamali" yang terdapat pada gambar nomor 3. Gambar tersebut merupakan sebuah visualisasi dari latar tempat dari halaman luas di malam hari dengan grading warna gelap serta tambahan aset sebuah pohon beringin besar dengan ayunan yang tergantung pada tangkai yang menjalar keatas, konsep ini merupakan sebuah imitasi dari alam realitas yang terdapat dalam alam indrawi dimana pohon beringin dinilai memiliki kesan angker karena bentuknya yang besar menjulang. Lombard (1996) menjelaskan bahwa sejak masa kerajaan, pohon beringin sudah dinilai sebagai pohon keramat bagi para rajaraja jawa. Penjelasan tersebut menjadi sebuah alasan terbesar mengapa masyarakat saat ini memiliki ketakutan tersendiri terhadap pohon tersebut bahkan dalam kisah folklore masyarakat banyak yang mengasumsikan bahwa pohon beringin merupakan pohon yang kerap kali dihuni oleh makhluk supranatural tidak kasat mata yang membangun ketakutan di masyarakat. Warna gelap pada latar visual di gambar nomor 3 jugan dapat membangun sebuah kesan keangkeran dalam game ini karena dalam realitanya konsep angker sangat dekat kaitannya dengan tempattempat yang gelap dan minim cahaya. Dengan berdasar pada penjelasan tersebut peneliti menyimpulkan bahwa konsep visual dalam gambar nomor 3 sudah sesuai dalam penilaian melalui kacamata seni sebagai imitasi.

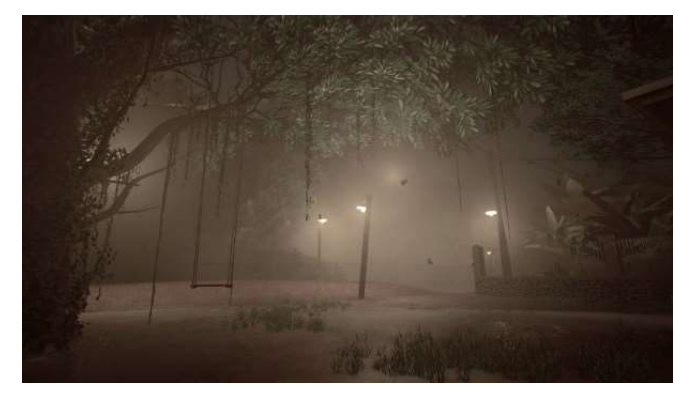

Gambar 3. Gambar latar game "Pamali"

Latar tempat dalam game "Pamali"sebagai game folklore dibuat sedemikian rupa agar mengandung unsur-unsur mistis yang mengundang rasa takut juga menegangkan bagi para pemain. Namun, konsep-konsep tersebut dibuat dengan tetap berdasar pada unsur folklore horor yang beredar di masyarakat. Hal tersebut merupakan sebuah konsep yang sesuai dengan kacamata penilaian seni sebagai mimesis, di mana konsep yang berdasar pada unsur folklore dijadikan sebagai landasan indrawi yang kemudian diimplementasikan melalui alam ide yang menghasilkan sebuah bentuk visual seperti yang terdapat pada gambar 4. Dalam gambar tersebut terdapat sebuah ilustrasi salah satu ruangan dari dalam rumah yang terlihat kotor dan berantakan seperti sudah 
lama tidak dihuni dengan grading warna yang terkesan remang-remang. Ilustrasi tersebut berdasar pada sebuah realita yang bersumber pada mitos masyarakat yang mengatakan bahwa rumah/ruangan yang kotor dan lama tidak ditempati akan diisi oleh unsur-unsur negatif dan mistis sehingga masyarakat memiliki ketakutan tersendiri dan enggan untuk mendekati rumah/ruangan yang memiliki kriteria seperti itu, game developer menerapkan konsep tersebut melaui elemen visual agar pemain dapat merasakan hal yang sama ketika mereka berada dalam kondisi dalam rumah dengan kondisi tersebut.

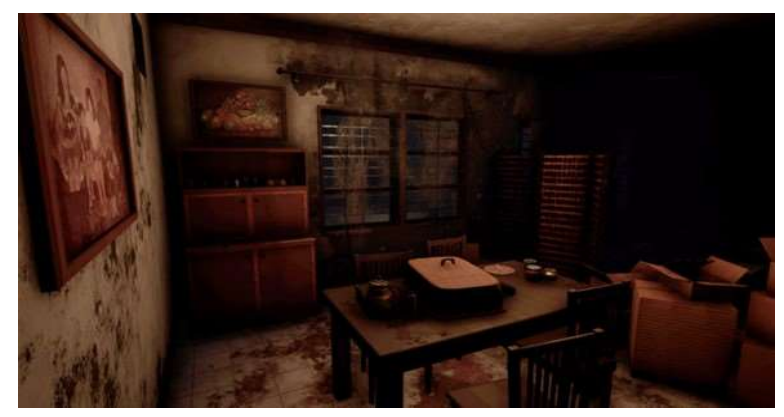

Gambar 4. Gambar latar ruangan game "Pamali"

Dalam menyempurnakan konsep yang ditentukan game developer merancang seluruh unsur-unsur pembentuk dalam sebuah game berdasar pada sebuah benang merah berupa cerita. Terlebih lagi dalam game dengan genre simulasi seperti "Pamali". Cerita mengikat keseluruhan konsep menjadi sebuah instrumen yang menarik untuk dilihat dan diikuti oleh para pemain, cerita yang baik tentunya memliki unsur-unsur pendukung yang membantu keberhasilan dari cerita itu sendiri. Karakter merupakan salah satu motor utama dari terciptanya suatu cerita yang baik begitupun sebaliknya, sebuah karakter tidak akan lepas dari cerita apakah yang ada dibalik karakter tersebut (Tillman: 2011).

Sebuah karakter didesain untuk berkomunikasi dengan pemirsanya. Cerita, informasi dan daya tarik dapat disampaikan dengan baik melalui peran dari sebuah karakter, pun demikian dengan game "Pamali" yang menjadi objek pembahasan kita. Dalam game ini, terdapat konsep visual dari sebuah karakter yang menjadi benang merah cerita yang disajikan dalam game ini, sebagai sebuah media untuk berkomunikasi dengan pemirsa/pemain karakter dalam game "Pamali" harus memiliki kedekatan personal kepada pemain sesuai dengan tema yang dirancang oleh game developer, yaitu folklore horor.

Dalam game ini hantu Pocong menjadi sebuah karakter pembentuk cerita yang diharap dapat berkomunikasi dengan baik kepada pemain dalam game ini. Hal tersebut dipilih karena karakter tersebut merupakan karakter yang terkenal dalam dunia folklore lokal di indonesia, karakter ini merupakan sebuah imitasi dari sebuah realitas alam indrawi yang dapat dirasakan oleh manusia yaitu kematian. Karakter ini merupakan implementasi dari wujud seseorang, khususnya masyarakat indonesia ketika sudah menjumpai ajalnya. Hal menyeramkan tentunya apabila kita bisa melihat wujud seseorang yang telah menjumpai ajalnya dapat berkeliaran disekitar kita karena alasan-alasan mistil yang berasal dari luar alam nalar manusia.

Realitas cerita inilah yang dimanfaatkan oleh game developer dengan tujuan menciptakan sebuah karakter yang memiliki cerita yang kuat sehingga mereka memilih melakukan imitasi dari wujud pocong kedalam bentuk visual sebuah karakter dalam game dengan harapan konsep karakter yang telah dirancang oleh seniman dapat melahirkan sebuah kesan yang sama ketika pemain bereaksi terhadap wujud menyeramkan dari karakter tersebut. 


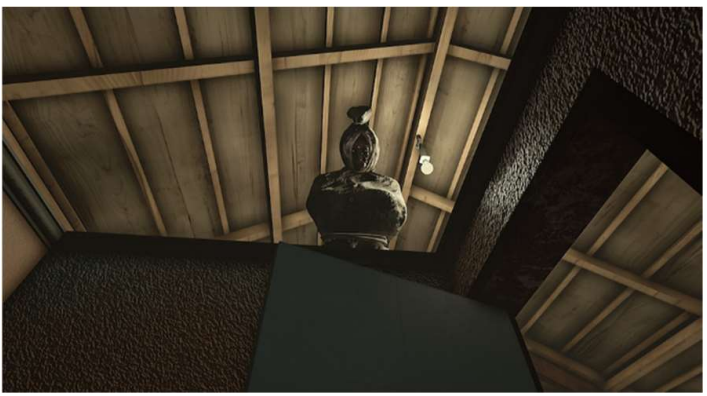

Gambar 6. Gambar latar game "Pamali"

\section{SIMPULAN}

Berdasarkan hasil pembahasan sebelumnya maka peneliti dapat menarik kesimpulan sebagai berikut:

1. Elemen Visual harus dapat merepresentasikan konsep/ide utama yang dibangun oleh perancang game.

2. Elemen Visual harus dapat menjadi sebuah jembatan penguhubung yang menghantarkan konsep, pesan, dan informasi yang di buat oleh perancang game. Dengan tujuan akhir dapat memberikan pengaruh persuasif bagi target khalayak sehingga dapat memberikan perhatiannya pada game ini.

3. Developer game dapat merealisasikan realita alam indrawi manusia sebagai formula di dalam konsep perancangan elemen visual dalam game mereka agar target khalayak dapat memahami ide yang ingin disampaikan oleh mereka.

4. Bentuk representasi realita game developer dapat diaplikasikan dengan cara mengambil gambaran dari apa yang memungkinkan atau berkaitan dengan alam indrawi sehingga bentuknya tidak harus realistis.

5. Metode penelitian filsafat seni sebagai mimesis dapat membantu peneliti dalam mengetahui konsep perancangan dan ide utama dari elemen visual dari game "Pamali".

6. Filsafat seni sebagai mimesis dapat dijadikan sebagai sebuah patokan dalam menciptakan sebuah hasil karya atau media yang mengandung nilai bagi seniman ataupun desainer

\section{DAFTAR PUSTAKA}

Danyati, R. (2018). Penerapan Mimesis Dalam Novel Empress Orchid Karya Anchee Min (Penelitian Analisis Isi). Prosiding Seminar Nasional Inovasi dan Tren (SNIT) 2018. C1C8.

Hakim, C. (2016, Juni 16). Kode Morse THR. Kompas Online. Diakses dari http://www.kompas.com

Johnson, B., \& Christensen, Larry. (2012). Educational Research: Quantitative, Qualitative, and Mixed Approaches ( $4^{\text {th }}$ ed). London: SAGE Publication Ltd.

Kementrian Pendidikan dan Kebudayaan RI. (2011). Peraturan Mendiknas tentang Satuan Pengawasan Internal (Permendiknas Nomor 47 tahun 2011). Jakarta: Penulis.

Kim, C., Mirusmonov, M., \& Lee, I. (2010). An Empirical Examination of Factors Influencing the Intention to Use Mobile Payment. Computers in Human Behavior, 26 (1), 310-322.

Lombard, D. (1996). Nusa Jawa: Silang Budaya. Warisan Kerajaan-Kerjaan Konsentris. Jakarta: Gramedia Nusantara.

Mulyadi, M. (2011). Penelitian Kuantitatif dan Kualitatif serta Pemikiran Dasar Menggabungkannya. Jurnal Studi Komunikasi dan Media, 15 (1), 127-138.

Tillman, B. (2011). Creative Character Deesign. Oxford: Elsevler.Inc.

Warsita, B. (2008) Teknologi Pembelajaran: Landasan \&Aplikasinya. Jakarta: Rineka. 
Young, R.F. (2007). Crossing Boundaries in Urban Ecology (Doctoral Dissertation). Tersedia dari Proquest Dissertation \& Theses Database. 